\title{
Biogas - A European Perspective on Safety and Regulation
}

\author{
Olivier SALVI, Samuel DELSINNE \\ European Virtual Institute for Integrated Risk Management (EU-VRi) \\ Stuttgart; 70174, Germany \\ Email: salvi@eu-vri.eu \\ www.eu-vri.eu \\ Sébastien EVANNO \\ Accidental Risk Division, Institut National de l'Environnement Industriel et des Risques (INERIS) \\ Verneuil-en-Halatte, France \\ E-mail: sebastien.evanno@ineris.fr \\ www.ineris.fr
}

\begin{abstract}
The production of biogas is positioned as energy which can not only generate a source of energy known as "green" but also which can recycle waste. In the context of sustainable development, the place of biogas is therefore essential. The risks corresponding to the production processes and uses of are still too little known. Several questions about the optimization of the production, the safety, the harmonization of the regulations and the need to develop standards are discussed in this paper, based on the results of a workshop on biogas safety and regulation organized in November 2010 by the authors.
\end{abstract}

Keywords: biogas, safety, regulation, anaerobic digestion.

\section{Introduction}

The development of new energies is experiencing a great development in the world and particularly in Europe. As a result, solar panels, wind turbines and other ecological technologies are more and more installed in many European countries and are constantly evolving. The main purpose of this development is to find an alternative energy replacing the fossil energy dependence which is more sustainable and reducing $\mathrm{CO}_{2}$ emissions. Thus, the impact on the environment is reduced and energy consumption is sustainable.

Biogas has a special major advantage in addition to other renewable bio-energies. Indeed, it reuses the waste as raw materials. The production of biogas is positioned as energy which can not only generate a source of energy known as "green" but also which can recycle waste.

In a context of sustainable development, the place of the biogas is therefore essential. However, the processes of anaerobic digestion are continually improving and new ideas for the uses of this gas continue to emerge.

However, the risks corresponding to processes of biogas production from biomass or waste are still too little known.

Several issues have appeared and need to be solved: the optimization of the production, the safety of the processes, the harmonization of the regulations and the need to develop standards (at European or International Level). 
To address these issues and find answers to these questions, INERIS and EU-VRi took the initiative to organize a European working group and a workshop on $24^{\text {th }}$ novembre 2010 in Paris.

The present document helps to share knowledge, to structure questions, and to propose answers and further actions aiming at improving safety of biogas production and supporting the quick and sustainable deployment of this energy.

\section{Context of the development of biogas}

\subsection{Background information}

Producing biogas is a recent technology which has two main advantages. Indeed, for few decades, governments have tried to develop this new energy because it is a sustainable energy and its raw materials are waste.

Unlike other renewable energy sectors, biogas production did not emerge from concerns on energy but rather from the environment (elimination of pollution, treatment of waste, control of greenhouse gas emissions). [Ref. 1]

The development of renewable energy is an important element of the energy policy of the European Union. The Renewable Electricity Directive (DIRECTIVE 2001/77/EC- [Ref. 15]) sets an indicative target of 22\% renewable electricity in gross consumption of the $\mathrm{EU}$ in 2020 and the Biofuel Directive (DIRECTIVE 2003/30/EC- [Ref. 16]) provides indicative targets of $5.75 \%$ substitution by biofuels by 2010 .

The European Strategic Energy Technology Plan (SETPlan) is part of the Energy and Climate Change policy framework. It contributes to the overall policy objectives by proposing, developing and implementing an Energy Technology Policy for Europe. It complements EU policy in energy and climate change and can enable cost effective compliance with legally binding targets. These include the realization of the internal market in electricity and gas; compliance with emission reductions and the revised and strengthened Emissions Trading Scheme; the increased contribution of renewable energies to the EU electricity generation; the measures to enhance energy efficiency; the EU car emissions standards; the negotiation of a post-Kyoto international agreement; and the development of an external energy policy. [Ref. 2]
Methanization makes it possible to produce biogas from organic elements of vegetal or animal origin. Biogas is a gas rich in methane, the same element that constitutes natural gas. Biogas can be directly tapped in subsurface containment centers (landfills) or produced using digesters (we can also speak about methanisers in this case). All organic materials except lignin are capable of being transformed into biogas. Effluents can be methanized in sewage purification plants. Liquid manure, agricultural waste and energy crops can be methanized in small-scale biogas units on farms or in co-digestion units (collective units that treat different type of wastes associated with a significant share of liquid manure). Solid municipal waste and green waste can also be transformed into biogas in large-scale solid waste methanization units.

European primary energy production from biogas reached 6 million toes (tons of oil equivalents) in 2007, i.e. a $21.2 \%$ increase with respect to 2006 (an additional 1 Mtoe) [Ref. 12].

The increase in biogas production principally benefited electricity produced in CHP (combined heat and power) units. With a $24.3 \%$ increase in $2007(+2.3$ TWh produced) CHP plant production reached 11.6 TWh, and represented a total electricity production which reached 19.9 TWh (+ 17.4\%).

Rubbish dump biogas continues to be the principal deposit exploited today: $50.6 \%$ of the total.

With a $14 \%$ share, sewage purification biogas is still behind all of the "other deposits" (principally agricultural biogas units). This type of biogas, the current driving force behind biogas growth in the EU, has the particularity of relying more and more on the development of dedicated energy crops (corn, etc.). These statistics only take into consideration biogas intended to be valorized, and not biogas that is burnedoff in flare stacks.

Current growth is not strong enough to reach the objective of the European Commission White Paper (15 Mtoe in 2010).

At the same time, the trend towards increases in the price of raw agricultural materials should curb growth of agricultural biogas production. Taking this situation into consideration, it is estimated a production at 8 Mtoe in 2010 (10\% annual growth). This production will represent $5.4 \%$ of the target of the European 
Commission "Biomass Action Plan” (SEC(2005) 1573 - [Ref. 24]) set at 185 Mtoe in 2010.

For the future, the target for the share of renewable energies set by the European Union is $20 \%$ in 2020. In addition, Biogas is one of the renewable energies that have most benefited from the strong increase in fossil fuel prices these last two years [Ref. 3].

Moreover, European Union regulations, limiting the discharge of waste in dump/landfills has played a large role in developing this sector, which today has widened its field of action into energy crops. For example, in Germany, biogas employs 13500 persons in direct and indirect full-time jobs and generates a turnover of $650 \mathrm{M€}$.

However, this source of energy is still too poorly studied from a safety point of view. Indeed, only few studies have been conducted to define the potential risks involved in producing and using biogas [Ref. 3].

\subsection{Production}

\subsubsection{The various raw materials and processes}

The main idea of the anaerobic digestion is to produce gas from waste. Biogas is the name of the gas produced and a biogas plant or anaerobic digester is the place where it is produced. The anaerobic digestion is the process which transforms organic matter into biogases such as methane and carbon dioxide. Wastes used in the processes must be organic and biodegradable in order to be digested by microorganisms in the absence of oxygen. Various types of organic waste can be found and therefore the following step of the production of biogas will differ because of the various raw materials. So there are several processes for the production of biogas, because it depends on the raw materials, but the main idea is still the same: to produce gas from waste. Indeed, biogas could come from several sorts of raw materials [Ref. 4]:

- Sewage sludge

- Food waste

- Waste from food industry

- Manure from cows, pigs etc.

- Residues from agriculture

- "Energy" herbs and plants like maize

- Distillery by products

- $\quad$ Organic fraction of municipal solid wastes
Fig. 1 Biogas processes

There are different sorts of raw materials and the amount of biogas or the quality of the biogas which will be produced from manure from animals will be different from the one produced from waste in the food industry. Thus, the biogas production is very variable from one plant to another. It is also important to highlight the difference between biogas plant and anaerobic digester (biogas from landfills and biogas from digesters).

The biogas production is sliced up in four major steps [Ref. 1]:

- Hydrolysis: large polymers are broken down by enzymes

- Acidogenesis: acidogenetic fermentations are most important, acetate is the main end product. Volatile fatty acids are also produced along with carbon dioxide and hydrogen.

- Acetogenesis: Breakdown of volatile acids to acetate and hydrogen.

- Methanogenesis: Acetate, hydrogen are converted to methane and carbon dioxide.

Fig. 2 Process of anaerobic digestion

Those steps are included in the main processes that are described in a bibliographical study on the anaerobic digestion [Ref. 5]. But some projects propose different processes like using aerobic/anaerobic digestion. Thus, there is not only one process but several pathways.

For anaerobic digestion of farm wastes, usually, there is not "aerobic/anaerobic/aerobic", but anaerobic and sometimes anaerobic as a post treatment of digestate (composting).

In this context, one can wonder if all these processes are equivalent regarding safety and what are the critical phases / steps.

\subsubsection{Relevant parameters}

Moreover in the anaerobic digestion process we can find several parameters [Ref. 1]:

- Humidity of the substrate: wet or dry

- Range of temperature: mesophilic or thermophilic

- Stage of fermentation: single stage or multiple stage

- Stock flow: continuous or discontinuous

- $\quad \mathrm{pH}$ control and temperature control 
Those examples illustrate the production variability, and it is probable that the yield of the production will depend not only on the raw materials used but also on the process.

In addition to the constant improvement of the technical aspects, technology becomes increasingly complex and it is then necessary to control, to measure and to monitor the continuous and instantaneous production with special devices. Those devices need to be reliable, accurate and long-lasting.

Quality or quantity of the gases produced seems to be also different. It depends on raw materials, sort of process, if gases are upgraded and how, or if other gases are removed and how. We previously saw that different raw materials or processes can produce biogas with different yields.

But in general, the biogases produced are methane (50$75 \%$ ), carbon dioxide (25-50\%), nitrogen (0-10\%), hydrogen sulfide $(0-4 \%)$, hydrogen $(0-1 \%)$, ammonia (0-500 ppm) and oxygen (0-2\%) [Ref. 1].

Sometimes industries add air in the biogas in order to remove $\mathrm{H}_{2} \mathrm{~S}$. This is one reason of the residual oxygen in the biogas. See Table 1 in source [Ref. 31].

Biogas contains small amounts of $\mathrm{H}_{2} \mathrm{~S}$ and some other pollutants. $\mathrm{H}_{2} \mathrm{~S}$ is poisonous when inhaled. Furthermore, when water is present, $\mathrm{H}_{2} \mathrm{~S}$ forms sulphuric acid $\left(\mathrm{H}_{2} \mathrm{SO}_{4}\right)$, which is highly corrosive, rendering the biogas unusable for pipes and reactors.

There are different ways to remove the unwanted gases, which mostly target the removal of $\mathrm{CO}_{2}$ [Ref. 19]:

- Chemical/ physical absorption

- High pressure water scrubbing

- $\quad$ Pressure swing adsorption

- Cryogenic separation

- Membrane separation

- Addition of air into the biogas

- Addition of $\mathrm{FeCl}_{2}$ in the digester
In this part there are a lot of technical aspects which depend on each other: Various raw materials mean different processes, different processes mean different amounts of gases, and different amount of gases mean different sorts of up-grading or removing... And finally, it appears impossible to fix a global yield in order to study all uses of biogas or to identify clearly hazards and risks in a biogas plant.

Then, it is important to understand:

- What are the safety critical parameters?

- Is it relevant to establish a regulation on the production of biogas or to think about a possible standardization?

\subsubsection{Profile of biogas plant/ producers}

Throughout the world, a countless number of designs of biogas plants have been developed under specific climatic and socio-economic conditions. Choosing a design is essentially part of the planning process. It is, however, important to familiarize with basic design considerations before the real planning process begins. This refers to the planning of a single biogas unit as well as to the planning of biogas-programs with a regional scope.

The performance of a biogas plant is dependent on the local conditions in terms of climate, soil conditions, the substrate for digestion and building material availability. The design must respond to these conditions. In areas with generally low temperatures, insulation and heating devices may be important. If bedrock occurs frequently, the design must avoid deep excavation work. The amount and type of substrate to be digested have a bearing on size and design of the digester and the inlet and outlet construction. The choice of design will also be based on the building materials which are available reliably and at reasonable cost.

Table 1. Trace compounds of biogas from different biogas production plants

\begin{tabular}{|l|l|l|l|l|l|l|l}
\hline Biogas & CH4 (\%) & CO2 (\%) & O2 (\%) & N2 (\%) & H2S (ppm) & Benzene $(\mathrm{mg} / \mathrm{m}$ 3 & Toluene $(\mathrm{mg} / \mathrm{m} \wedge 3)$ \\
\hline Landfill & $47-57$ & $37-41$ & $<1$ & $<1-17$ & $36-115$ & $0,6-2,3$ & $1,7-5,1$ \\
\hline Sewage digester & $61-65$ & $36-38$ & $<1$ & $<2$ & b.d. & $0,1-0,3$ & $2,8-11,8$ \\
\hline Farm biogas plant & $55-58$ & $37-38$ & $<1$ & $<1-2$ & $32-169$ & $0,7-1,3$ & $0,2-0,7$ \\
\hline
\end{tabular}

Note: b.d.: below detection 
High sophistication levels of biogas technology require high levels of skills, from the planner as well as from the constructor and operators. With a high training input, skill gaps can be bridged, but the number of skilled technicians will get smaller the more intensive the training has to be. In addition, training costs compete with actual construction costs for scarce (project) resources. Higher technical sophistication also requires more expensive supervision and, possibly, higher maintenance costs. To which extent prefabricated designs are suitable depends largely on the cost of labor and transport. [Ref. 6]

There are various types of plants. Concerning the feed method, three different forms can be distinguished:

- Batch plants

- Continuous plants

- $\quad$ Semi-batch plants

Batch plants are filled and then emptied completely after a fixed retention time. Each design and each fermentation material is suitable for batch filling, but batch plants require high labor input. As a major disadvantage, their gas-output is not steady.

Continuous plants are fed and emptied continuously. They empty automatically through the overflow whenever new material is filled in. Therefore, the substrate is generally fluid and homogeneous, even though solid feeding is quite common for farm biogas plants. Continuous plants are suitable for rural households as the necessary work fits well into the daily routine. Gas production is constant, and higher than in batch plants. Today, nearly all biogas plants are operating on a continuous mode.

Up to now, usually farm digesters are fed in semicontinuous mode (several feedings per day).

If straw and dung are to be digested together, a biogas plant can be operated on a semi-batch basis. The slowly digested straw-type material is fed in about twice a year as a batch load. The dung is added and removed regularly. [Ref. 6]

Concerning the construction, three main types of simple biogas plants can be distinguished:

- fixed-dome plants

- floating-drum plants

- lagoon-based plants
But also other types of plants play a role, especially in past developments. In developing countries, the selection of appropriate design is determined largely by the prevailing design in the region. Typical design criteria are space, existing structures, cost minimization and substrate availability. The designs of biogas plants in industrialized countries reflect a different set of conditions.

Biogas could be produced at different scales: a smallscale by farmers and large-scale by industrials. A lot of parameters depend of the scale such as design, process, and raw materials. Moreover, using the technology of biogas production requires knowledge in order to control the process of the production. But in Switzerland, courses exist at different levels teaching biogas plant operators and managers of wastewater treatment plants. These have a federal certification.

Then, in this context, it is important to understand: What is the education in the various countries? How to obtain a permit to operate a plant? Is education for operator appropriate?

\subsection{Uses}

One of the most interesting advantages of producing biogas is that it has several applications and uses. Indeed, because biogas is composed of multiple gases, it is not only used for energy.

\subsubsection{Combustion}

The first application of biogas is heat when it burned. The Lower Heating Value (LHV) of the combustion is between 6.0 and $7.0 \mathrm{kWh} / \mathrm{m}^{3}$, whereas the LHV of the natural gas is about $10.3 \mathrm{kWh} / \mathrm{m}^{3}$ [Ref. 7]. This heat could be used in the process but biogas could also generate electricity. The electricity yield of cogeneration is around $35 \%$. The yield depends on raw materials and type of biogas plant. And during combustion, some toxic gases are generated. Hence, it is necessary to study the composition of the gas and to remove toxic gases or future toxic gases before combustion.

\subsubsection{Injection in natural gas grid}

From a technical point of view, those yields are worse than some other forms of energy production and that is 
why the one from biogas still needs to be improved. But for the moment, biogas is a good alternative for replacing fossil energy, because it is a renewable and ecological energy. As yields need to be improved, the safety in biogas applications needs to be further studied. For example, the integration in gas-grid biogas might cause risks as the ANSES (Agence Nationale de Sécurité Sanitaire de l'alimentation, de l'Environnement et du travail) explains in its report in 2008, but there is no additional risk when compared to natural gas [Ref. 20].

The next paragraphs describe the state of the art in some European countries:

In Germany, the feeding of biogas into the natural gas grid is an efficient energy solution, even if the sites where gas is used are far away from the sites where it is produced. Feeding gas into the grid is facilitated via a compressor, a device raising the pressure level of the biomethane to that of the gas in the closed pressurized lines of the grid. Given European regulatory realities, new gas producers have the opportunity to feed gas into the conventional gas grid. For biogas generators, this multiplication of the possible number of consumers is attractive. For purposes of feeding-in, however, the gas must be up to the quality specifications of the relevant legal provisions and may only deviate within the range of these quality standards. Such standards are obtained using technologies for reconditioning gas. Because a non-negligible quantity of energy is necessary for gas compression, the energy balance and the economic feasibility of the compression and feed-in process must be reviewed on a case-by-case basis. With regard to feeding biomethane into the natural gas grid, it is necessary to distinguish the exchange gas and accessory gas. The difference lies in the quality of the gases. An exchange gas has the same qualitative standards as conventional natural gas and can be exchanged in the grid as such. Accessory gas possesses a composition that is not equivalent to that of the natural gas, and can therefore only be mixed into the grid beneath a certain threshold. Regulations distinguish between low-quality natural gas ("Erdgas L") and high-quality natural gas ("Erdgas $\mathrm{H}$ ”). Erdgas $\mathrm{H}$ possesses higher methane content, and is used mainly in the GUS federal states and extracted principally in the North Sea. Erdgas L contains roughly $89 \%$ flammable gases (primarily methane, but also small amounts of ethane, propane, butane, and pentane), while Erdgas $\mathrm{H}$ contains about 97\% flammable gases (the same as those listed for Erdgas L). The types of natural gas available in Germany vary with geography. Similarly, the degree to which biomethane is upgraded depends on the region from which it comes [Ref. 8].

In Sweden, there are 38 sites of biogas injection (Laholm, Helsingborg, Göteborg, Stockholm) and several projects of injection because of an economic context very propitious. It is possible to add propane in order to increase the Wobbe Index [Ref. 20].

In Switzerland, since 1995, some experiences of injection have been gained. It is not allowed to inject biogas from landfills in gas-grid and to improve the quality of combustion for the other biogases. Also there are currently 15 sites of biogas injection. There are two types of injection:

- unlimited injection, for a biogas pure at $96 \%$ of methane

- limited injection, for a biogas composed at least $60 \%$ of methane [Ref. 20].

In Austria, biogas is injected since 2005 in Lisbod and there are several projects in progress. However, it is not allowed to inject biogas from landfills [Ref. 20].

In France, some experimentation has been performed since 1998 and a project is confirmed in Lille Sequedin [Ref. 20].

In The Netherlands, since 1987, landfill biogas is injected in four sites and biogas from sewage sludge since 2006. Moreover, experimentation on several upgrading processes has been managed [Ref. 20].

In Luxembourg 3 large cooperative biogas units are in construction. They will mostly rely on the treatment of organic household/municipal wastes and agricultural residues. The biogas will be upgraded to biomethane using either the water scrubbing or amine absorption techniques.

Furthermore at least 7 operations in Sweden, more than 30 in Germany, 5 in Austria have been reported but to compare them it is necessary to clarify the definition of an injection site. 
In a nutshell, as reported in Ref. 19 several projects have been carried out in order to establish specifications for integrating biogas in gas-grids. They have to be assessed and the results shared to propose a common approach in Europe.

\subsubsection{Biogas for vehicles}

The biogas could also be used as a fuel in Natural Gas Vehicle. There are currently strong incentives for increased use of renewable fuels in the transport sector worldwide. Some bioethanol and biodiesel production routes have limitations with regard to resource efficiency and reduction of greenhouse gases. More efficient biofuel systems are those based on lignocelluloses and novel conversion technologies. A complementary strategy to these is to increase the production of biogas from the digestion of organic residues and energy crops, or from byproducts of ethanol and biodiesel production. Compared with other biomass-based vehicle fuels available so far, biogas often has several advantages from an environmental and resource-efficiency perspective. This provides the motivation for further technological development aiming to reduce costs and thereby increase economic competitiveness of biogas as a vehicle fuel [Ref. 35].

But the biogas needs to be highly purified. Thanks to this technique, replacement of diesel or petrol by biogas reduces the emissions and also the engine noise considerably [Ref. 20]. This is an interesting aspect, because the number of vehicle users is growing days after days. But the integration of biogas as a fuel is a recent application and only few projects work on it in Europe [Ref. 22]. Those projects try to study the application with a city scale in 14 cities. But is this possible in a larger scale?

Thus, biogas vehicle fuel stands out as a promising alternative, together with the 'second generation' vehicle fuels that are based on lignocellulose. Compared to the majority of the liquid biofuels in use today, biogas often has a far better performance with regard to both area efficiency and life cycle emissions, and it is therefore a strong potential candidate for becoming one of the most sustainable vehicle fuels in the near future [Ref. 36]
Using biogas for vehicle is a promising solution but before using this method for public vehicle, some research on safety is necessary.

\subsubsection{Some limitations}

The biogas process is the most complicated of the three biotechnological processes. A consortium of microorganisms catalyses the degradation of complex organic molecules and it results in the production of methane and carbon dioxide as well as some heat.

This process remains technically underdeveloped and several crucial aspects need to be addressed. The volumetric productivities need to be raised substantially and the conversion rate of generated digestate improved to reduce the volume of biofertilizer generated. Overcoming these limitations will result in the production of increased amounts of gas, while generating less biofertilizer with a higher nutrient content. The volumetric productivities of processing the biomass feedstock to the final biofuels will strongly influence the investments needed to make the technology commercially viable.

In the future there will be an increased demand for land to produce biomass for food and animal feed, chemicals, materials and energy. Therefore, it is important to prioritize processes, production systems and products that are efficient with regard to the land area used and the use of organic byproducts and wastes, and also according to their environmental impact, particularly in terms of reduction of greenhouse gas emission.

\section{Safety aspects}

\subsection{Main hazards}

There are risks in a biogas plant such as explosion, toxicity (leak of $\mathrm{H}_{2} \mathrm{~S}$ ) and microbiological risks. The construction of a biogas plant and its maintenance should be well monitored in order to manage risks. Prevention of people from being exposed to those risks and checking of all materials (including corrosion) should be realized with the aim of making the production of biogas safer. 


\subsubsection{Explosion}

The risk of explosion is the most studied because it is related to the production and use of an explosive gas which is composed mainly with methane. But some explosions happen regularly. It means that the risk of explosion is always present in a biogas plant because of the mixture air/biogas.

A recent incident in UK was caused by the substrate foaming up and ripping the digester hood [Ref. 14].

Table 3: Example of some gases explosion properties

\begin{tabular}{|l|c|c|c|}
\hline Gases & $\begin{array}{c}\text { LEL } \\
(\% \mathrm{v})\end{array}$ & $\begin{array}{c}\text { UEL } \\
(\% \mathrm{v})\end{array}$ & $\begin{array}{c}\text { Flame speed } \\
(\mathrm{m} / \mathrm{s})\end{array}$ \\
\hline Acetylene & 2.5 & 82 & 2.66 \\
\hline Carbon monoxide & 12.5 & 74 & - \\
\hline Hydrogen & 4.1 & 74.8 & 2.6 \\
\hline Methane & 5 & 15 & 0.39 \\
\hline
\end{tabular}

Source: [Ref. 14]

\subsubsection{Toxicity}

The second major risk is toxicity related to the leak of $\mathrm{H}_{2} \mathrm{~S}$, because this gas is very toxic and we know that this gas is one of the most abundantly produced in anaerobic digestion. The most important case of this risk was the accident which happened in Zeven in November 2005. Four people died because of the exhaust of a cloud of hydrogen sulfide in unusually high concentrations.

It has been reported also that biogas plants could cause environmental disasters such as in Barßel in September 2002. 20 tons of fish were killed because high quantities of substrate were spread in the environment.
In order to have a better use of biogas or to avoid the spread of contaminant gases, the methane has to be removed from other gases such as ammonia, siloxanes... Then those gases once separated might be accidentally released into the atmosphere and generate toxic risks.

\subsubsection{Microbiology}

The microbial risk is also important and several studies have emphasized this risk. Introducing the biogas produced into systems constructed for natural gas is currently causing a debate about the risks of introducing pathogens to the gas systems. Finally, risks for disease transmission from processed (upgraded and dried) biogas can be judged as being low. The possible exposure of working personnel is probably the most significant risk. However, this group could be easily identified and informed about potential risks and how they can be managed. The risk of inhaling pathogens when using gas is overshadowed by the risk of gas intoxication and explosions or similar, since these effects would probably occur before a dose of pathogens high enough to cause an infection had been ingested. The biogas produced in the systems analyzed is therefore considered safe to use even in kitchen cookers [Ref. 34].

Furthermore the microbiological risks also exist at the beginning of the process. I.e. in the handling by the personnel of organic (waste products)

Therefore it is important to keep in mind the following questions:

Are the risks of biogas known by the operators?

Are the safety management systems in place adequate?

Table 4. Example of some gases toxicity thresholds:

\begin{tabular}{|l|c|c|c|c|l|}
\cline { 2 - 5 } \multicolumn{1}{c|}{} & \multicolumn{2}{c|}{ In European Union } & \multicolumn{2}{c|}{ In United States } & \multirow{2}{*}{ LD(50) in mg/ $\mathrm{m}^{3}$} \\
\cline { 2 - 5 } \multicolumn{1}{c|}{ Gases } & TLV & STEL & TLV & STEL & \\
\hline Ammonia & 14 & 36 & 17 & 24 & 7600 during 2 hours \\
\hline Carbon monoxide & 55 & - & 29 & - & 2670 during 4 hours \\
\hline Dichloride & - & 1.5 & 1.5 & 1 & 1185 during 1 hour \\
\hline Hydrogen sulfide & 7 & 14 & 14 & 21 & 617 during 4 hours \\
\hline
\end{tabular}

TLV: Threshold Limit Value based on normal 8-hour workday - STEL: Short-Term Exposure Limit. (in mg/ m3) LD(50): Lethal Dose measured with a group of rats - Those values might be carefully compare because of the various exposure times.

Source: [Ref. 13] 


\subsection{Learning from experience - Accident records}

\subsubsection{Accident data bases}

Generally, there is a lack of communication of accidents and their analysis. In fact, when accidents occurred in biogas plants, in general, only the local media describes the circumstances of the accident and little information on the analysis of the causes is disseminated. There is a lack of feedback and learning from experience.

\subsubsection{Results of research in some data bases}

Several accident databases report about accidents involving biogas productions or uses, such as ARI, FACTS

After a search on ARIA [Ref. 9] and FACTS [Ref. 10] websites, here are feedbacks of some accidents:

\section{8/11/2005 - GERMANY - RHADEREISTEDT}

In a production of biogas from organic waste recovery, an offshoot of hydrogen sulfide (H2S) kills three people and a truck driver who came to unload waste from a slaughterhouse. A severely intoxicated person is hospitalized. The extremely high concentration of H2S in the lobby complicates the response of firefighters and a dozen have suffered of poisoning. An important aeration (more than $24 \mathrm{~h}$ ) will be required before allowing access to the building. Arriving in the evening, the truck from The Netherlands was parked outside the hotel until morning. The tragedy occurred when the load of the truck was unloaded within a closed hall to reduce odor nuisance, in a pit of $100 \mathrm{~m}^{3}$ with 2 agitators whose lid can be closed because of the failure electric motor that actuates it. The materials discharged (waste slurries sulfide, $\mathrm{pH}$ close to 8.5 and a temperature of $60^{\circ}$ ), are guts and viscera of pig. (loaded 24 hours earlier and as usual).

The reaction between these substances and materials already in the pit (waste animal or dairy, low $\mathrm{pH}$ according to the analysis conducted after the accident) would be the cause of the strong release of $\mathrm{H}_{2} \mathrm{~S}$. The temperature of the environment and the functioning of the agitation would have favored the dispersal of toxic gas in the lobby of unloading. Moreover, the extraction device located at the bottom of the pit which rejects stale air outside through a biofilter would have been insufficient. An investigation has been conducted.

\section{7/01/1999 - FRANCE - LA ROCHETTE}

In a recycling unit of biogas from the anaerobic treatment plant of a paper mill, an explosion (5 kg of TNT) buffer destroyed a balloon of flexible material 10 $\mathrm{m}$ and their associated piping supplying a boiler or steam flare safety. The balloon exploded, the railings are bent in a radius of $3 \mathrm{~m}$, the tiles are destroyed within a radius of $20 \mathrm{~m}$, cladding and windows on the unit up to $130 \mathrm{~m}$ fly into pieces away. There has been no victim. The balloon will be blocked and downhill into depression. Air would be entered by Teflon joints rubbing on the central axis. The biogas has come back and then has formed the explosive mixture which has been ignited by the pilot flame of the flare. An accidental production of hydrogen in the digester and an act of malice were also discussed. Expertise was made. Safety devices were then installed (analyzers, valves, etc.).

\section{2/03/1997 - ITALY - PESCHIERA DEL GARDA}

In a municipal sewage plant wastewater, an explosion occurred during repair work in a concrete silo of a biogas plant. Residue gas and welding operations are the cause of the accident. Two workers were thrown out and killed, and a third one falls to the bottom of the building and was seriously injured. The roof of the silo has been blown.

\subsubsection{Conclusions}

We can see that safety devices are sometimes not sufficient and some problems appear during maintenance. It is necessary to learn from those experiences in order to never do these mistakes again. That is why it is necessary to communicate accident feedback and risks assessment.

The establishment of a permanent network sharing information on causes of accidents involving biogas would be helpful to avoid repeating the same errors. This network should operate at EU or international level. 


\section{Regulation}

\subsection{Situation in different European countries}

The upgrading and feeding of biogas into the natural gas grid is currently not subject of consistent European regulation. The parameters and basic conditions, however, are phrased in Directive 2003/55/EC of the European Parliament and of the European Council of 26 June 2003 concerning common rules for the internal market in natural gas and repealing Directive 98/30/EC. In Chapter 1 of this Directive, biogas and gas from biomass are explicitly included in the scope of the regulation. In Paragraph 24 of the Preamble, the European Parliament and the European Council declare the following:

"Member States should ensure that, taking into account the necessary quality requirements, biogas and gas from biomass or other types of gas are granted nondiscriminatory access to the gas system, provided such access is permanently compatible with the relevant technical rules and safety standards. These rules and standards should ensure that these gases can technically and safely be injected into and transported through the natural gas system and should also address the chemical characteristics of these gases" [Ref. 8].

As of 2009, not all European countries have implemented regulations on the upgrade and feed-in of biogas.

\subsubsection{Germany}

The political framework for the feed-in of biogas to the natural gas grid in Germany is defined by a variety of regulations which reflect the complex value chain stages with different challenges on every stage. An overview can be found here.

The most influential parameter is the ongoing implementation of the Energy and Climate Programme of the German Federal Government. Since upgraded and fed-in biogas is currently not yet on a competitive basis with natural gas, the Energy and Climate Programme provides a toolbox to develop the market demand.

The legal framework envisages a broadly diversified application field for biomethane, including pure heat applications, combined heat and power generation with state-guaranteed feed-in tariffs according to the
Renewable Energy Source Act (EEG), as well as applications as biofuel in natural gas-dedicated vehicles. The Energy and Climate Programme consists of 29 courses of action focusing on climate protection. The central measures in context with the injection of biogas are listed in the following:

Section 2: Amendment to the Renewable Energy Source Act (EEG)

The amendment to the EEG became effective on January 12009.

Section 9: Regulations on the injection of biogas into natural gas grids

This section was implemented on April 122008 by means of the ordinance to promote the use of biogas in the existing gas network. The ordinance includes the following measures:

- Gas Network Access Ordinance (GasNZV)

- Gas Network Tariffs Ordinance (GasNEV)

- Incentive Regulation Ordinance (ARegV) and

- $\quad$ Electricity Network Tariffs Ordinance (StromNEV)

With the commencement of the adapted Gas Network Access Ordinance on April 12 2008, the conditions for the feed in of biogas to the natural gas grid were decidedly improved. Moreover, in Paragraph 41a, the ordinance defines the goal early phrased in the Energy and Climate Programme on the promotion of the injection of biogas: Until the year 2020, up to 60 billion $\mathrm{kWh}$ biogas are to be fed every year into the natural gas network, and 100 billion kWh biogas until 2030. This dimension corresponds with the potential for this technology as determined in an influential study by the German Technical and Scientific Association for Gas and Water (DVGW) of 2006.

Section 14: Renewable Energy Heat Act (EEWärmeG) The Renewable Energy Heat Act (EEWärmeG) also became effective on January 12009.

Section 17: Promotion of biofuels

- Amendment of the Biofuel Quota Act

- Ordinance on requirements regarding the sustainable generation of biomass for biofuel applications: Biomass Sustainability Ordinance (BioNachV)

The law on renewable energy was amended on the 6th of June 2008. From 2009 onwards, the digression of the feed in tariff for biomass will be changed from $1.5 \%$ to 
$1 \%$. The feed in tariff for one $\mathrm{kWh}$ of electricity coming from biomass for plants under $150 \mathrm{kWe}$ will amount to $€ c 11.67 / \mathrm{kWh}$. The premium for electricity produced from agricultural biogas will be raised from $€ c$ 6/kWh to 7 for plants below $500 \mathrm{kWe}$. To this will be added a premium for production units using more than 30\% liquid manure (€c 4/kWh for plants under $150 \mathrm{kWe}$ and $€ c 1 / \mathrm{kWh}$ for plants under $500 \mathrm{kWe}$ ) or a premium of $€ \mathrm{c}$ $2 / \mathrm{kWh}$ if the main source is waste coming from the cleaning of natural green spaces for units below 500 $\mathrm{kWe}$. The premium for cogeneration will be raised from $€ \mathrm{c} 2 / \mathrm{kWh}$ to 3 for plants below 20 MWe and the technology premium will be maintained. Another innovation will be that units producing purified biogas will benefit from a premium which will depend on the plant efficiency: €c 2/kWh for units producing 350 Nm3 per hour and $€ \mathrm{c} 1 / \mathrm{kWh}$ for units producing up to 700 Nm3 per hour. The new law also foresees the increase of the feed in tariff for electricity produced from landfill gas for units up to $500 \mathrm{kWe}$, thus passing from €c $7.11 / \mathrm{kWh}$ to $€ c \mathrm{c} / \mathrm{kWh}$ and the continuation of the $€ \mathrm{c}$ $6.16 / \mathrm{kWh}$ tariff for plants up to 5MW. The tariff will remain unchanged for sewage sludge biogas: $€ c$ 7.11/kWh up to $500 \mathrm{kWe}$ and $€ \mathrm{c}$ 6.16/kWh up to $5 \mathrm{MW}$. In parallel, the German government passed a new law on 12 March 2008 concerning injection into the gas network, in order to promote the injection of biomethane (purified biogas). The aim of this new law is to replace $10 \%$ of natural gas consumption with biogas as of 2030. As for electricity produced from renewable sources, the law gives biomethane suppliers priority for injecting their output into the natural gas network. It also stipulates that a large share of the costs shall be borne by the network operator and not by the supplier.

\subsubsection{Switzerland}

In Switzerland, the SVGW ("Schweizerischer Verband des Gas- und Wasserfaches“, Swiss Association for Gas and Water) has published the Directives G 13, "Directives on the injection of biogas into the natural gas network". These directives define requirements for the quality of biogas from fermentative processes and of similar gases if an injection into the natural gas network is planned. Furthermore, the directives define requirements regarding the feed-in technology plants. The overall goal of the directives is to ensure the reliability of the feed-in plants, the natural gas distribution networks as well as installed gas units.

The directive SUVA (Safety in biogas plant) is another regulation of Switzerland.

\subsubsection{France}

The renewable energy objectives in France are defined by the 13 July 2005 law which plans that $10 \%$ of the French energy needs will be insure by renewable sources by 2010. 3 clear targets are defined in order to meet the overall objective. Firstly, the share of national renewable electricity production should reach $21 \%$ of the electricity consumption by 2010. In 2007 this share is about $12.8 \%$ (source: the 10th worldwide electricity production from renewable energy sources). Secondly, a $50 \%$ increase in the heat production coming from renewable sources. And thirdly, a $7 \%$ increase in the share of biofuels used for transport.

Two important instruments have been put in place to fulfill the objectives. A system of purchase prices for the renewable electricity sector and an income tax credit (reimbursement by the tax departments) for household equipments.

A new law on environment perspectives named 'Grenelle 1' is in way to be voted by the French assembly. This law confirms the willingness of the country to diversify its energy sources and to meet the long-term target of 20\% of renewable energy by 2020 .

The production of primary energy from biogas is equally divided between biogas from landfill sites (161.3 ktoe in 2007) and biogas from waste treatment plant (144.2 ktoe). Other biogas sources represent only $1.2 \%$ of the total (3.78 ktoe). An order dated 10 July 2006 defines the feed-in-tariff of electricity produced from methanization biogas. It varies from $9 \mathrm{c} € / \mathrm{kWh}$ for installations of less than $150 \mathrm{kWe}$ to $7.5 \mathrm{c} € / \mathrm{kWh}$ for installations of more than 2 MWe. In addition, there is an energy efficiency incentive of $3 \mathrm{c} € / \mathrm{kWh}$ for installations that optimize heat recovery and/or electricity generation. This rate is not applicable to landfill site biogas which (under an Order dated 1st October 2001) benefits from a buying price of between $4.5 \mathrm{c} €$ and $5 \mathrm{c} €$ per $\mathrm{kWh}$, plus an energy incentive of between $0 \mathrm{c} €$ and $0.3 \mathrm{c} €$ per $\mathrm{kWh}$.

Currently, the feed-in of biogas to the natural gas grid is not yet permitted in France, although (or possibly 
precisely because) the feed-in of upgraded landfill gas was carried out in context with the MONTECH project in 1998. This project, however, was stopped due to discussions on the necessary gas quality and possible gas network contamination.

The "Agence Nationale de Sécurité Sanitaire de l'alimentation, de l'Environnement et du travail" has spoken in favour of the injection of biomethane into the natural gas grid on October 292008 with the prospect of applying it as biofuel. A specific regulatory framework coming from the ANSES conclusions on the admission of biogas to the natural gas network has not yet been published. The technical conditions for the access to the natural gas grids of the gas network operators are, however, already created in such a way as to principally allow the injection of renewably generated gases.

\subsubsection{Sweden}

In Sweden, the SS 155438 standard "Motorbränslen Biogas som bränsle till snabbgående ottomotorer", which became effective in 1999, regulates the quality criteria for biogas utilised as biofuel.

Biogas Type A refers to vehicles without oxygen sensor; Type B applies to vehicles with an oxygen sensor, also called lambda sensor. Similarly, this standard also applies to the injection of biogas into the natural gas networks. Comparably to the injection of substitute gas in Germany, however, an adaptation of the fuel value is required before access to the gas network is permitted.

The backdrop of this regulation focusing on usage as vehicle fuel is twofold: the biomethane produced in Sweden is almost exclusively used as biofuel, and the Swedish gas network infrastructure is less developed than it is, for example, in Germany. Thus, it has so far been possible to inject biogas into the natural gas network only in some areas on the Swedish west coast. Only a few injection projects have therefore been implemented so far.

No rules are regulating injection of biogas to the gas grid. Upgraded biogas is only injected into the distribution grid and not the transmission grid. In general the rules for natural gas are valid for plants connected to the natural gas grid. Deals about injection and connection are closed between plant owners and grid owners. Deals also cover amounts, price and quality of the gas. Work is in progress concerning e.g. quality responsibility.
The green gas principle is used and biogas can be sold anywhere along the natural gas grid even though the costumer does not receive biogas, but gets natural gas. There is work in progress on this subject.

In Sweden the biogas production has been more or less constant the past years, which is also true for the total number of plants. However, there is a change in where the biogas comes from. The production from landfills decreases as expected, while the production from sewage treatment plants and co-digestion plants increases.

Upgrading of biogas and injection to the gas grid In Sweden, there are 8 sites of injection in Sweden among the 40 upgrading plants (it seems that the number of injection sites have been mixed up with the number of upgrading plants). There are 115 filling stations. In Sweden the biggest environmental benefit is gained, by upgrading biogas and replacing fossil transport fuels. $19 \%$ of the produced biogas is utilized as vehicle fuel. During 2007, 28 million of Nm3 biogas was sold as vehicle fuel, which is more than the amount of natural gas (about 25 million Nm3) sold as vehicle fuel in 2007. 14400 vehicles (buses, heavy cars, light cars) were riding on gas (biogas and natural gas) in 2007. End of December 2007 there were 86 public gas filling stations and 27 gas fill-in stations for buses, now those numbers have reach a total of 115 filling station

\section{Policy measures}

The introduction of biogas as vehicle fuel in Sweden has been realised by many governmental and local support measures, such as:

- A 30\% investment support from governmental investment programmes to many biogas plants;

- A special investment support of M€ 15 for biogas filling stations during 2006 and 2007;

- Exemption of biogas use as vehicle fuel from tax;

- Relative low natural gas tax of $1.4 € \mathrm{ct} / \mathrm{kWh}$ (3.9 $€ / G J)$ compared to a tax of $7.7 € c t / k W h(21.4 € / G J)$ for petrol;

- Free parking for biogas cars in several cities like Gothenburg;

- Readiness of the gas suppliers in trying to keep the biogas price about $20-30 \%$ below the equivalent price of petrol, as long as the market for biogas as vehicle fuel is under development. 
- New car tax since October 2006. Tax based on fuel and $\mathrm{CO}_{2}$ emissions. Gas models reduced with about $50 \%$ compared to petrol.

- Obligation to provide biofuels at filling stations.

- $1100 €$ subsidy for new Eco-cars.

- Exception from congestion tax in Stockholm from 1 August 2007 for gas vehicles, ethanol and electricity hybrids.

Regarding the environmental targets, the government's policy is that $85 \%$ of all new governmental cars should be Eco friendly, as well as $25 \%$ of all new emergency services vehicles.

\subsubsection{Austria}

Renewable energy policy in Austria exists on three levels: the Federal level, the regional level of the provinces (Bundesländer) and the local level of municipalities. Important contributions from renewable energy sources regard large hydropower for electricity, biomass for heat and power and solar thermal installations. On the Federal level the programme klima:aktiv (started 2004 by the Federal Ministry of Agriculture, Forestry, Environment and Water Management) aims at reducing $\mathrm{CO}_{2}$-emission and increasing the penetration of renewable energy sources. Regarding renewables, focus is on biogas and biomass, solar thermal and heat pumps. Typical for the Austrian programmes is that they are easily accessible through the internet and through telephone hotlines.

The klima:aktiv programme has biogas as one of the priorities. Special focus in this programme is on providing information (conferences, networking events, and training), communication and research.

In 200762 waste landfill gas recovery plants, 134 sewage sludge digesters, about 350 (agricultural) codigestion plants, 25 industrial anaerobic waste water treatment plants, and about 15 biowaste digestion plants from municipalities were in operation in Austria. These plants produced between 265 and 414 million Nm3 biogas, from which $45 \%$ from (agricultural) codigestion plants, and $47 \%$ from landfills and sewage sludge. Based on the feed-in tariffs set in 2006, it is possible to get a subsidy of $17 €$ cents/kWh with an installed capacity of $100 \mathrm{~kW}$ or less guaranteed for 10 years. As a result of economic pressure through increased raw material costs, rarely new plants were opened in 2007.
In Austria, the injection of biogas is possible either via the existing gas network or via a local micro gas network.

The injection of landfill gas or sewage gas into the public gas grid is currently generally not permitted.

The political framework for the injection into the public gas grid is defined in the following legal regulations:

The Gas Economy Act ("Gaswirtschaftsgesetz") obliges gas grid operators to grant grid access to biogenic gases. These gases do need to fulfill the quality criteria defined in the "General Distribution Network Conditions" to ensure safe transport within the Austrian gas network. Regulations $\mathrm{G} 31$ and $\mathrm{G} 33$ define these criteria.

ÖVGW Regulation G 31 (ÖVGW = Austrian Association for Gas and Water) defines all those parameters and quality criteria, which are necessary to ensure safe transport. Moreover, the regulation determines the required gas fuel value data. The quality criteria phrased in the regulation refer to the characteristics of the imported gas.

ÖVGW Regulation G 33 applies to the injection of biogas based on renewable processes into the natural gas networks. This regulation therefore defines the quality of renewable gases and the quality control which are preconditions for the feed-in.

Besides the fact that some aspect of the production of biogas in general has a regulation, there is no specific regulation for biogas plants.

Indeed, there are regulations at the plant construction, at the safety level as ATEX or at economic level. But as regards the safety to the production and use, the regulation is virtually nonexistent.

\subsection{ATEX Directive}

Because there is methane in biogas, biogas production is concerned by the ATEX directives.

There are two ATEX directives (one for the manufacturer and one for the user of the equipment) [Ref. 11]:

- The ATEX 95 equipment directive 94/9/EC, Equipment and protective systems intended for use in potentially explosive atmospheres;

- The ATEX 137 workplace directive 99/92/EC, Minimum requirements for improving the safety and health protection of workers potentially at risk from explosive atmospheres. 
INERIS is a major referent in the implementation of these guidelines at European and international levels.

Regarding equipments, some companies provide devices, which are used in biogas production, with the ATEX labels. But at small-scale of biogas production, those devices are hardly used.

Concerning the workplace, obligations are complex and require special attention. Safety measures have to be well managed because of the presence of possible explosive atmosphere and in order to satisfy the minimum requirements.

\subsection{BREF - "Slaughterhouses and Animals By- products Industries" [Ref. 22]}

The BREF has been published in May 2005, by the European Commission. This report is a Reference Document on Best Available Techniques (co-called BREF) in the Slaughterhouses and Animal By-products Industries and particularly on Biogas production.

In single stage digesters, biogas cannot be produced from pure animal material because the nitrogen content is too high. Animal waste must, therefore, be mixed with other organic matter to reduce the nitrogen content. In Denmark, approximately $75 \%$ of the biomass resource for anaerobic digestion is animal manure, with the remainder mainly originating from food processing, including slaughterhouses, although some segregated domestic waste is also treated. Animal by-products, manure and the sewage sludge from slaughterhouses can all be treated.

It is also reported in this report that there is a risk of an accident release of $\mathrm{CH}_{4}$, which is a greenhouse gas and has a global warming potential 30 times greater than that of $\mathrm{CO}_{2}$. But the advantages associated with biogas production from slaughterhouse by-products include: a reduction in the concentration of impurities in waste water, low excess sludge production and the production of a biologically stable excess sludge that can be used as a fertilizer. The solid residues from biogas production from animal by-products may be composted. The use of such compost is subject to the restrictions specified in ABP Regulation 1774/2002/EC.
For each unit of electricity generated from biogas, 1.5 units of heat may be produced as hot water at over $80^{\circ} \mathrm{C}$. The energy-rich gas can be used, e.g. in slaughtering or animal by-products production, as a substitute for conventional primary energy. Biogas is reported to make no net contribution to the greenhouse effect.

This document reports that a biogas plant could generate noise pollution. Indeed, large-scale mechanical equipment such as compressors, used to aerate the process fluid and filtration plant may be potential sources of noise pollution.

\subsection{Results of commonalities and differences}

The first commonality which we can see in the different regulations is that governments want to increase the number of biogas plants and the use of biogas for the next years in order to enforce the European directive and energy plans.

But differences appear at the next step: the price of energy, such as electricity, is not the same in the various countries of Europe. It results that specifications and requirements are different, because legal amount of energy production is linked to its price.

Concerning the thresholds of dangerous trace compounds in biogas, regulations are broadly similar.

Finally, the main problem of biogas related to safety is that regulations are enforced for large-scale production but there is a lack of enforcement of those one for small-scale production and, in general, it is because of a lack of skills.

In addition, the enforcement practices can vary from one Member State to the other, and therefore they have to be harmonized to guarantee the same development of biogas in a single European market.

\section{Standardization/ Guidelines}

The application of standards makes an industry more efficient and safer and this could be an interesting solution to improve safety in biogas plants.

For larger biogas programs, especially when aiming at a self-supporting dissemination process, standards in dimensions, quality and pricing are essential. Standard procedures, standard drawings and forms and standardized contracts between the constructor, the planner, the provider of material and the customer avoid mistakes and misunderstandings and save time. There is, 
however a trade-off between the benefits of standardization and the necessity of individual, appropriate solutions.

But nowadays there is no biogas standard. The Standardization Administration of China has made a proposal to the International Organization for Standardization (ISO) for a new field of technical activity on biogas in January [Ref. 23].

The table of contents of this standard would be:

- Biogas glossary

- Designing, construction, commissioning and check and test of small biogas facilities (household biogas pool)

- Designing, construction, commissioning and check and test of large- and middle-scale biogas plants

- Designing, manufacturing, installation and inspection of biogas equipment

- Designing, manufacturing and inspection of products for biogas application

- Designing, manufacturing, installation and inspection of equipment and facilities for biogas power generation

- Comprehensive use of digested solid and liquid

- Appraisal on technical, economical and environmental benefit of biogas facilities

The European Committee for standardization has created a working group in order to find a common standard on the Injection of non-conventional gases into gas networks. The reference of this group is CEN/TC 234/WG 9. The injection of biogas into gas grid is concerned by this research.

\section{Outcomes of the workshop}

As part of the work described in this paper a workshop on "Biogas - Safety and Regulation" took place in Paris on November 24, 2010. The workshop was organized by INERIS and EU-VRi and gathered 34 experts from all over Europe.

The main objectives of the workshop were:

- Share information, in particular on projects, processes but also on safety and regulation in order to identify the state of the art in these fields across Europe.

- $\quad$ Find and understand the gaps in terms of safety and regulation.
- $\quad$ Propose solutions to fill those gaps and possibly prepare the base of a permanent network on safety aspects.

The main outcomes of the workshop are summarized in the next paragraphs.

\subsection{Safety issues}

The first part of the event was dedicated to the safety issues. Indeed, some research on safety has been led by institutes like INERIS and by industrial companies such as GDF-SUEZ or RHODIA in order to analyze the risks and to improve the safety along the production and the uses of biogas. Some risks appear important and well studied such as explosion and hydrogen sulfide release but it has been reported that the microbiological risk is also important and not well studied.

For example, the safety distances based on the effects corresponding to the hazardous phenomena (heat flux, overpressure and toxicity) have to be considered in order to analyze and quantify the risks. Those distances depend on the pressure, the composition of the biogas and the type of biogas (from: agricultural waste, municipal waste, wastewater treatment plant...). The study made by INERIS shows that the agricultural process can be in some conditions more dangerous than the other processes [Ref. 36]

Regarding the uses of biogas, GDF-SUEZ has carried out some studies which demonstrated that the CNG (Compressed Natural Gas) could be less dangerous than the diesel, looking at the criticity which combines the severity and the probability of the events. The tank of vehicle which uses biogas contains safety devices. Moreover, there exists a regulation R110 which describes the requirements of the tank aspects and its tests. The risk analysis is essential to develop safely the uses of biogas.

Considering the current situation, from the discussions during the workshop, it can be concluded that safety has to be improved based on the existing regulations that have to be better enforced.

It also appeared necessary to increase the awareness of the workers and promote prudent behaviors by involving them in the safety management process: participation in risk analysis (HAZOP, preliminary risk 
analysis...), analyze near-misses and accidents; raise level of knowledge related to safety... (See 6.3).

Biogas production or use generates several various risks such as explosion, toxic releases but also microbiological risks, often neglected.

Risk analysis is a key element of the safety management system of biogas facilities and has to be performed involving the workers.

\subsection{Key production parameters and data}

The risk analysis enables to identify the key parameters which are relevant to ensure safe production facilities and safe uses. Some of these key parameters are subject to regulation.

In the framework of several projects, data and key production parameters are produced and compiled in some European institutes such as HSL, INERIS or SP. These projects are running in parallel without exchanges at the moment.

Some parameters are relevant regarding the safety or the production: for example, the pressure and the temperature in the digester. It has also been reported that the presence time in the digester and the load balancing are important for the production efficiency and the safety. The amount of contaminants in the biogas is also relevant but there is no special best upgrade and moreover it depends on the raw materials. Thus the composition of the raw materials has to be controlled and certified. The composition of the raw material and of the biogas is very important because they play a major role in the risks analysis.

Pooling data is important to ensure a quick return on investment and to start up collaborative projects on production, safety and uses connected with biogas.

During the workshop, based on the presentations, it was suggested to share some findings and data when possible and to explore the opportunity and benefits to compile those data in a database at the European scale and on all sectors of biogas taking into account that those pieces of information are sensitive. This database could support the regulations and the standardization.
From the workshop it appears necessary to create at the European scale a database gathering relevant key production parameters, data and safety methods to ensure the quick and safe development of the biogas sector.

\subsection{Learning from experience}

Learning from experience based on near-misses and accidents is necessary to avoid repeating mistakes or errors. It is part of the risk analysis process to improve safety of the operation.

The feedback of SIAAP presented during the workshop was a great opportunity to understand the benefits of the learning from experience process. SIAAP had an accident some years ago and they have worked on a method to learn from this experience and have started the investigation and analysis. Then, SIAAP has updated all the plants: production devices, maintenance, and approach of risks.

In addition, during the investigation, they realized that the regulation applying to their installations is very fragmented and the enforcement difficult at the design phase (by engineering companies). Thus they decided to create a guideline on regulations and practices in order to make easier the implementation of the safety requirements.

The example of the Naturalgaskielen in Luxembourg shows that agricultural facilities can be safe if they implement standards (German standards).

With its strict method of risks analysis derived from the Chemical industry, Rhodia has observed a reduction of the number of accidents. Mostly, accident root causes are linked to human factors, mistakes or errors in the design, when building or during operations of the facilities. Thus Rhodia has focused on the safety program on its employees. The safety approach used by Rhodia consists in using tools in order to analyze the risks, to qualify and quantify objectively the effects. This approach helps to consider all safety aspects.

Learning from experience and sharing it may force people to consider safety as a major challenge. 
The workshop concluded that safe production or uses improve the image of the biogas sector and will improve its efficiency.

Creating a network and a platform on biogas safety and sharing best practices will improve safety performance and support the quick development of the biogas industry.

\subsection{Safety of biogas production processes}

Safety aspects are difficult to assess because they depend on several elements, such as the types of technology, types of facilities, the size of the site, the upgrading technology and the lay-out of the installations, and the staff and organization in place. There is also a combined productivity and safety problem due to the raw materials inconstancy (amount and composition). Thus it is important to perform a specific risk analysis which will depend on the composition of the products and on the specific features of the facility.

Considering accident investigations it appears that often accident sequences are similar in their root causes and consequences. Thus there is a clear added value in sharing experience, feedback and results of accident investigations, and also the risk analysis in a global approach for all situations.

In a nutshell, in spite of the fact that each plant is specific, it is possible to define a global safety approach and a common risk analysis by sharing information, methods and data.

For safety in the regulation, it is relevant to notice the difference between the production and the uses and between the physical process and the biological one regarding safety.

The complexity of the safety assessment is due to the fact that each plant is specific because of the technology, the staff and organization in place and the local context. Thus it appears necessary to perform risk analysis for each installation and to share results of accident investigations among the personnel, but also in a larger forum.

\subsection{Implementation of the existing regulation}

After a short introduction on this issue, it was obvious that the implementation of safety regulations on biogas plants is not harmonized throughout Europe.
In addition, the main message from the discussion on the implementation of the existing regulation is that the main problem regarding the regulation is not the regulation itself but its implementation. Ignorance, fragmentation and in some cases lack of enforcement are observed.

Most of the participants agreed that the regulation on biogas has to be developed in a way that it could support the safe development of the biogas industry. Because of the diversity of the processes and uses, it seems necessary to adopt rather a goal-based approach instead of a descriptive approach. This will give more flexibility and efficiency to achieve a high safety performance.

At the end of the workshop, a remark on the quality of waste was pointed out. Waste is becoming a "precious raw material”, for example Luxembourg imports waste. Thus it could be necessary to have a certification of "quality" for the waste. Indeed a certification on waste quality will allow a better control of the digestion and improve the biogas quality. It is important to notice that the presence of toxic gases depends on the waste "quality”.

The existing regulation seems appropriate but should be better implemented.

Goal-based regulation appears more effective than descriptive regulation because of the diversity of technologies and configurations, and because the technological improvement is still on-going.

\subsection{Sharing best practices and education of the operators}

One of the current problems which have been identified is the lack of knowledge related to risks for the persons involved in the biogas sector, in particular for the agricultural biogas. Thus, it is necessary to improve education and dissemination of knowledge on safetyrelated aspects. However, it has to be done in a careful way without demonizing biogas.

There is also a technical problem due to detection equipments which operate in a "contaminated environment" and not in a "clean air". Indeed, the measurement of hydrogen sulfide in the biogas is 
different as in the air. Sensors for detections and measures have to be carefully selected.

It is important to disseminate information related to the risks in biogas to operators, or farmers but also design engineers because everyone has to be aware, and sometimes, even at high-level, risks are not well-known. Indeed, in general, simple-looking facilities such as biogas plants might contain similar safety critical situations, as complex facilities. In all cases, risk analysis has to be performed and risk analysis methods and tools have to be made available to engineers and operators working on biogas.

There was an agreement that a single accident with severe consequences happening in the biogas industry may damage the whole sector, the whole industry image. Thus, the participants agreed to play an active role in sharing information and promoting safety.

It is important to define guidelines on best practices at European level to improve convergence if not harmonization in the various European countries.

In France, regulations (ICPE 2781-1 regulation and ATEX regulation) adopted recently requires that staff working in the field of biogas has to undergo safety courses. This is an interesting example of measures to address the problem of lack of safety knowledge and awareness.

Dissemination of information on risks connected with biogas is necessary. Every employee should be involved in the safety assessment.

Best practices have to be better shared to develop rapidly and safely the biogas energy in Europe.

The participants recommended to create a platform to exchange on safety issues.

\section{Conclusions and perspectives}

This paper presents a review of the situation on biogas production and uses, and the perspectives that it offers in the context of the recent European Energy policies. It points out that proper safety management and adequate regulation will ease the quick deployment of this technology, but there are still some issues to be solved.

Regarding the production and uses of biogas, it is important to discuss and share best practices and to reach a harmonization at least at EU level.
The main insurance for the safety in the biogas sector is the risk analysis. Thus it is important to work on the improvement of the systematic performance of risk analysis.

It is important to create a network and a database on biogas safety in order to develop safely the biogas sector. Because a major accident could have a negative impact for each actor in the biogas industry, these network and database will give the impulse to share knowledge and best practices to prevent any accident. Thus it is necessary to pursue in this way and create a platform to share safety information and best practices.

The workshop was fruitful and experts have shared information and ways of thinking about safety and regulation. This action should be repeated in a broader context.

\section{Acknowledgements}

This paper was elaborated with the contribution of the members of the Programme Committee of the workshop presented in the paragraph 6. They are here acknowledged for their contribution:

ARRHENIUS Karine (SP Technical Research Institut, Sweden), COENEN Joep (RHODIA, Netherlands), FOUQUET Rémi - THIÉBAUT Charles - GAUCHET Lucille (MEDDTL, France), GRENINGER Aude (GDF-SUEZ, France), HOFFMANN Lucien \&

DELFOSSE Philippe (CRP Gabriel Lippmann, Luxembourg), KAY Jake (HSL, United Kingdom), MARCHAIS Caroline (ATEE / Club Biogaz, France), MEMBREZ Yves (EREP SA, Switzerland), MOLETTA René (MOLETTA METHANISATION SAS, France), NEDELEC Ronan \& RIOTTE Michel (SIAAP, France). 


\section{References}

References are to be listed in the order cited in the text. Since the paper addresses a topic in quick development a lot of the information was taken from the web.

A. Websites visited last time in November 2010

1. www.eubia.org/108.0.html

2. http://ec.europa.eu/energy/technology/set_plan/set_plan_ en.html

3. www.energies-renouvelables.org/barometre.asp

4. www.unu.edu/unupress/unupbooks/80434e/80434E0j.ht $\mathrm{m}$

5. www.3a-biogas.com/infocenter/executive_summary.htm

6. www.arizonaenergy.org/AltEnergyClub/Biogas\%20\%20Application\%20and\%20Product\%20Development.ht $\mathrm{m}$

7. www.biogas-renewableenergy.info/biogas_composition.html

8. www.biogaspartner.de/index.php?id $=10093 \& \mathrm{~L}=1$

9. www.aria.developpement-durable.gouv.fr/

10. www.factsonline.nl/

11. www.ineris.fr/fr/ressources/recherche/atex

12. www.eurobserv-er.org

13. www.osha.gov/SLTC/healthguidelines

14. www.reptox.csst.qc.ca/RechercheProduits.asp

B. Document in Portable Document File (PDF) version

15. http://eur-

lex.europa.eu/LexUriServ/LexUriServ.do?uri=OJ:L:2001 :283:0033:0033:EN:PDF

16. http://eur-

lex.europa.eu/LexUriServ/LexUriServ.do?uri=OJ:L:2003 :123:0042:0046:EN:PDF

17. www.lth.se/fileadmin/energiportalen/Filer/Om_Energipor talen/Invigning/Posters/Energy_analysis_of_biogas_prod uction_Maria_Berglund_P_l_B_rjesson.pdf

18. http://students.chem.tue.nl/ifp24/BiogasPosterWEB.pdf

19. www.afsset.fr/upload/bibliotheque/058412092985118807 049572120143/biogaz_oct08.pdf

20. www.ieabiogas.net/Dokumente/Biogas\%20upgrading.pdf

21. http://213.131.156.10/xpo/bilagor/20040115134708.pdf

22. http://eippcb.jrc.ec.europa.eu/reference/brefdownload/do wnload_SA.cfm

23. http://publicaa.ansi.org/sites/apdl/Documents/News\%20a nd\%20Publications/Links\%20Within\%20Stories/ISO\%2 0TSP\%20211\%20\%28Biogas\%29.pdf

24. http://eurlex.europa.eu/LexUriServ/LexUriServ.do?uri=COM:200 5:0628:FIN:EN:PDF

25. www.kas-bmu.de/publikationen/kas/KAS_12.pdf

26. www.ineris.fr/centredoc/dradrc93-scenarios-accidmethanisation-web.pdf

27. www.ineris.fr/centredoc/Rapport_Biogaz_web.pdf
28. www.ineris.fr/centredoc/methaniseur_agricoles_medad_ Biogaz_web.pdf

29. www.ineris.fr/centredoc/reacteur-pilote-methanisationweb.pdf

30. www.ineris.fr/centredoc/risques-sanitaires-biogazweb.pdf

C. Books

31. S. Rasi, A. Veijanen, J. Rintala. Trace compounds of biogas from different biogas production plants, Energy, Volume 32, Issue 8, August 2007, Pages 1375-1380

32. A. Jaffrin, N. Bentounes, A. M. Joan, S. Makhlouf. Landfill Biogas for heating Greenhouses and providing Carbon Dioxide Supplement for Plant Growth, Biosystems Engineering, Volume 86, Issue 1, September 2003, Pages 113-123.

33. B. Vinneras, Caroline Schonning, Annika Nordin. Identification of the microbiological community in biogas systems and evaluation of microbial risks from gas usage, Science of The Total Environment, Volume 367, Issues 2-3, 31 August 2006, Pages 606-615.

34. M. Poeschl, Shane Ward, Philip Owende, Prospects for expanded utilization of biogas in Germany, Renewable and Sustainable Energy Reviews, Volume 14, Issue 7, September 2010, Pages 1782-1797

35. P. Borjesson, Bo Mattiasson. Biogas as a resourceefficient vehicle fuel, Trends in Biotechnology, Volume 26, Issue 1, January 2008, Pages 7-13.

36. S. Evanno, Accidental scenario and modeling of effects distances connected with agricultural-scale and industrial-scale biogas plant. Ref. INERIS DRA-09101660-12814A, available at www.ineris.fr 
Fig. 1 Biogas processes

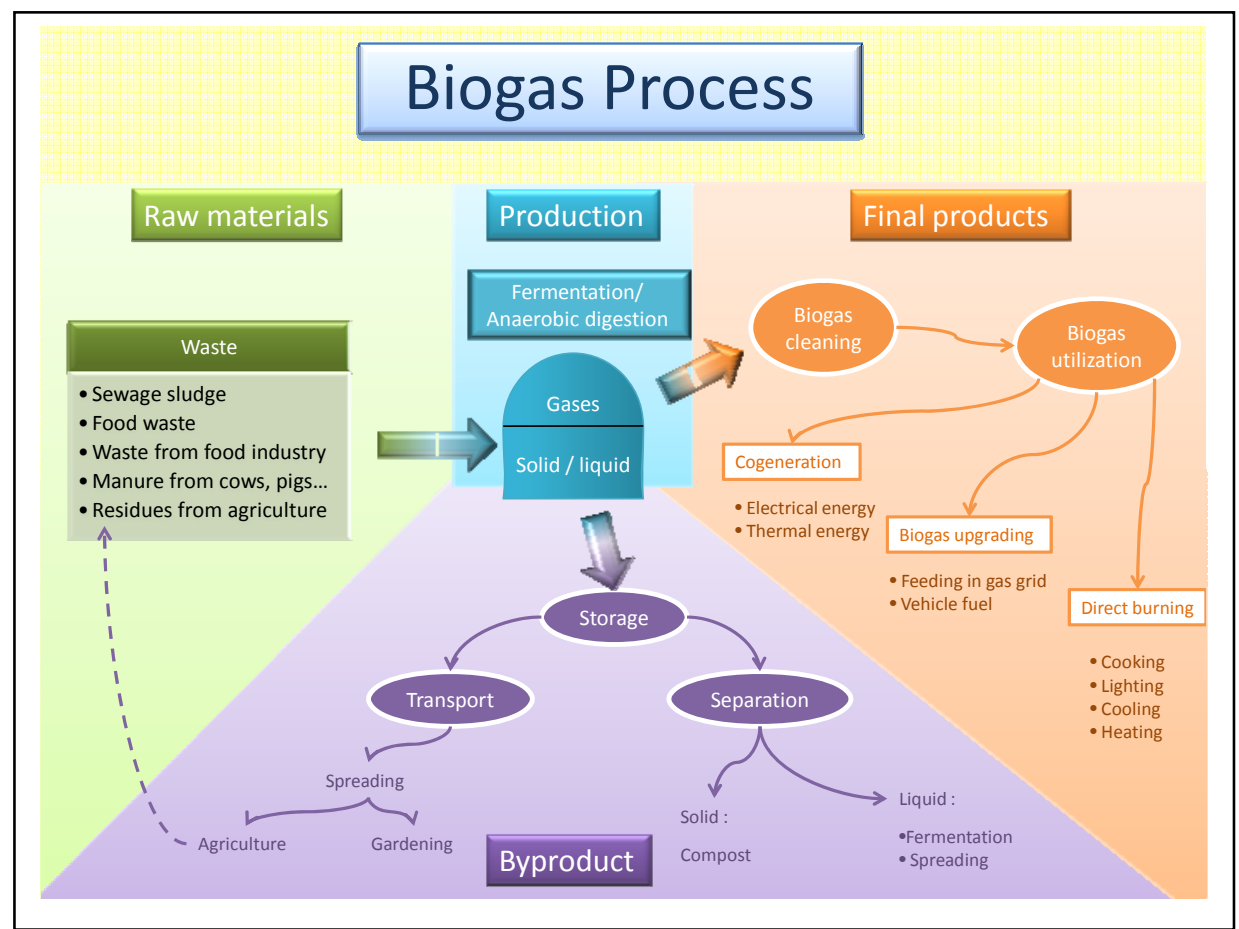

Fig. 2 Process of anaerobic digestion

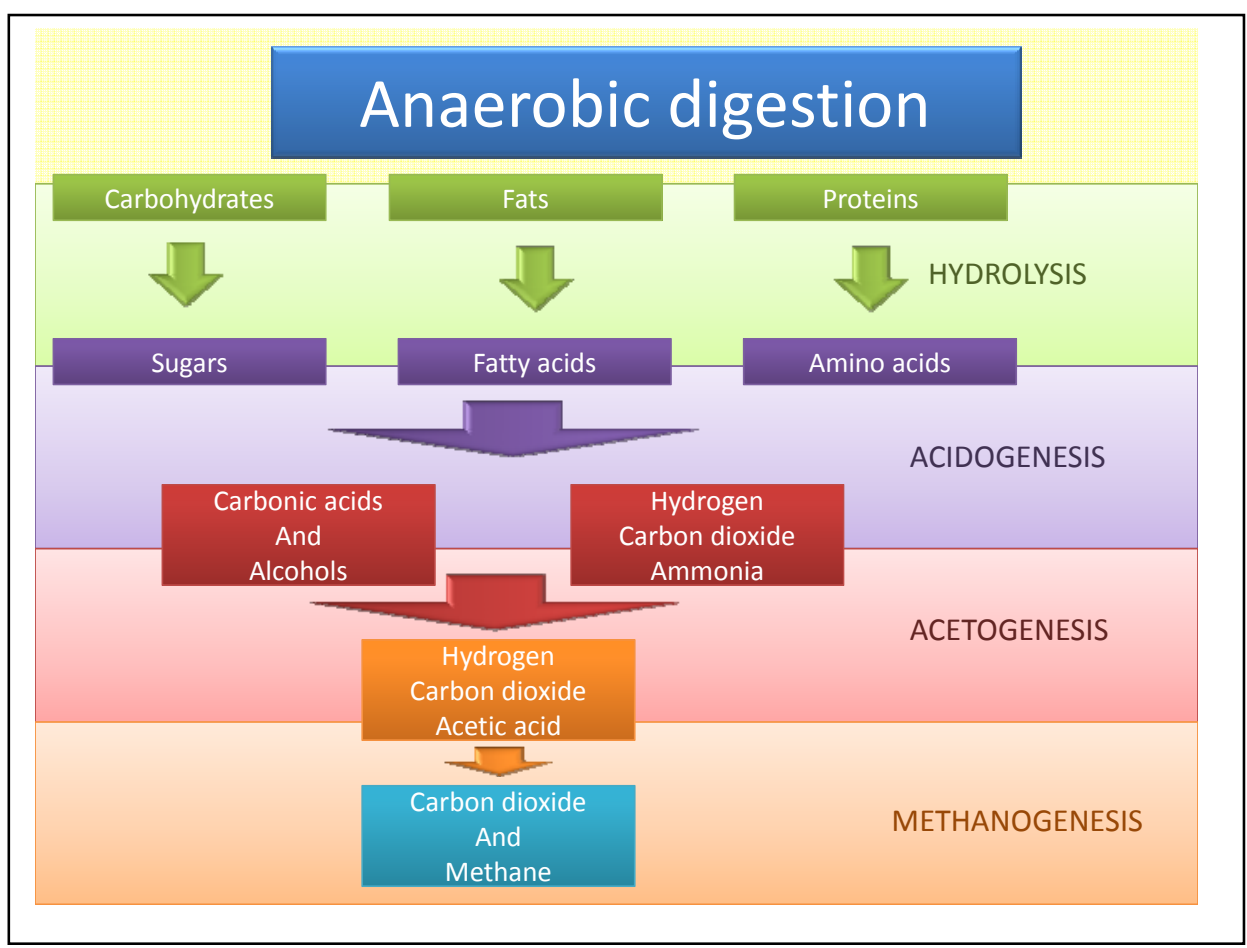

